\title{
Design por analogia impulsionado pela tecnologia: biomimética como exemplo.
}

Design by analogy driven by technology: biomimetics as an example.

KAYAT, Claudia; Mestre em Design; Departamento de Artes \& Design - PUC-Rio claudiakayat@puc-rio.br

MAGALHÃES, Claudio; Doutor em Design; Departamento de Artes \& Design - PUC-Rio claudio-design@puc-rio.br

\section{Resumo}

Desenvolver a capacidade criativa é importante para os designers, pois a mesma pode influenciar o sucesso de um novo produto, marca ou serviço, diferenciando-os pela novidade e qualidade, aumentando sua competitividade e gerando inovação. Segundo Robinson (2001), o processo criativo pode ser aprendido, desenvolvido e sistematizado por meio de diversas ferramentas e técnicas. Nesse artigo apresentaremos uma delas que é o uso de analogias, especialmente analogias biológicas como a biomimética - impulsionada pela tecnologia, que transfere informação e significado de um sujeito particular (natureza) para outro sujeito particular (por ex.: produtos) na busca por inovação e inspiração.

Palavras Chave: criatividade; analogias; biomimética.

\section{Abstract}

Developing creative capacity is important for designers because it can influence the success of a new product, brand or service, differentiating them by novelty and quality, increasing their competitiveness and generating innovation. According to Robinson (2001), the creative process can be learned, developed and systematized through various tools and techniques. In this paper we will present one of them, namely the use of analogies, especially biological analogies such as biomimetics - driven by technology, which transfers information and meaning from one particular subject (nature) to another particular subject (eg products) in the search for innovation and inspiration.

Keywords: creativity; analogies; biomimetic. 


\title{
1 Criatividade para inovar
}

"A criatividade é o coração do design, em todos os estágios do projeto" (BAXTER, 1998, p.85). Desenvolver a capacidade criativa é importante para os designers, pois a mesma pode influenciar o sucesso de um novo produto, marca ou serviço, diferenciando-os pela novidade e qualidade, aumentando sua competitividade e gerando inovação.

Ken Robinson, PhD, (professor emérito de Educação na Universidade de Warwick, Reino Unido), explica que criatividade é um processo de desenvolver ideias originais que contenham valor. Em seu livro (Libertando o Poder Criativo), ele explica a importância da criatividade:

\begin{abstract}
Não importa quem você é nem o que faz, se está vivendo no planeta Terra está em meio a uma revolução global. (...) As duas grandes forças que movem essa dinâmica são a inovação tecnológica e o crescimento populacional. Juntas, elas vêm revolucionando nossa forma de viver e de trabalhar; esgotam os recursos naturais do planeta e mudam a natureza da política e da cultura. (...) Considerando a velocidade da mudança, empresas e governos reconhecem que a educação e o treinamento são as chaves para o futuro, e enfatizam a crucial importância de desenvolver a capacidade criativa e inovadora. Em primeiro lugar, é essencial gerar ideias para produtos e serviços novos e para a manutenção da competitividade. Em segundo lugar, precisamos que a educação e o treinamento capacitem as pessoas a um maior grau de flexibilidade e de adaptação, de forma que as empresas consigam acompanhar as mudanças dos mercados. (ROBINSON, 2001, p.21).
\end{abstract}

A National Academy of Engineering (NAE), em publicação Educating the Engineer of 2020 (2005), apontou que as habilidades de inventividade prática e criatividade serão os diferenciais necessários para os projetistas em 2020, e afirmou que os profissionais capazes de criar e desenvolver produtos e serviços inovadores serão mais bem pagos (NAE, 2005).

Porém, ainda segundo Robinson (2001), há um entendimento equivocado de que somente pessoas especiais são criativas. A Criatividade é uma capacidade mental inerente a qualquer ser humano e deve ser estimulada. O processo criativo pode ser aprendido, desenvolvido e sistematizado, por meio de diversas técnicas. Robinson explica de que forma novas rotinas e hábitos de pensamento podem liberar a energia criativa:

\footnotetext{
É possível pensar de forma original em todas as atividades. No ritmo diário de nossas vidas, naturalmente adotamos rotinas de comportamento e hábitos de pensamento. Quando encontramos um problema ou uma situação nova, nossos costumes já incorporados podem dificultar a identificação de soluções originais. Existem diversas ferramentas e técnicas para ajudar a liberar formas de pensamento que escapem do convencional, entre elas o pensamento lateral ou divergente. No pensamento lógico-dedutivo, as ideias se apoiam umas nas outras em movimentos cuidadosos e consistentes e levam a um número limitado de respostas possíveis (ou a apenas uma solução). Os pensamentos lateral e divergente funcionam por meio de associações bem mais livres: muitas vezes por meio de metáforas ou de analogias, ou mesmo da reformulação da pergunta com o objetivo de ampliar as possibilidades (ROBINSON, 2001, p.157).
}

A Rede de Pesquisas da Mente em Albuquerque (Novo México, EUA), quer ir além, e busca comprovação científica para explicar os processos criativos. Pesquisadores, liderados por Rex Jung, professor assistente do departamento de neurocirurgia da Rede, estão mapeando o cérebro humano para saber que tipo de impulsos bioquímicos e reações físicas ocorrem durante as atividades criativas. $\mathrm{O}$ estudo, com sessenta e cinco pessoas, sugere que a criatividade prefere caminhos mais lentos e sinuosos do que a inteligência. No caso da inteligência, esclarece Jung (2010), o cérebro parece ser uma super-rodovia eficiente que o leva do ponto A para o ponto B. 
Mas, nas regiões do cérebro relacionadas à criatividade parece haver rotas alternativas e estradas auxiliares pequenas e sinuosas, caracterizando um processo mais lento entre o ponto $\mathrm{A}$ e $\mathrm{o} \mathrm{B}$. Jung também explica que há dois movimentos cruciais para o modo de pensar criativo: a divergência (ampliar perspectivas, fazer associações diferentes, recorrer a conceitos novos), e a convergência (ter foco nas aplicações práticas das novidades). $O$ indivíduo criativo sistematiza seu processo: sabe quando aplicar técnicas de fluidez criativa e analogias, a fim de gerar muitas ideias, e também sabe o momento de focar na solução e desenvolvê-la, para implementá-la com sucesso. "Criatividade é essa capacidade de ver possibilidades que os outros não enxergam e contribuir com algo original e útil" (JUNG, 2010).

\subsection{Raciocínio por analogia}

Entender o processo cognitivo envolvido na formação de analogias é importante para melhorar o processo criativo. Os psicólogos americanos Gentner e Markman (1997) fizeram diversas pesquisas para entender as etapas do processo no raciocínio humano por analogia. Descobriram que é um processo baseado principalmente em observação, associações, comparações, correspondências, semelhanças, similitudes, memória, mapeamento e combinação de conhecimentos e conceitos que em princípio não estavam relacionados, gerando assim, soluções originais. Em sua pesquisa Structure Mapping in Analogy and Similarity, os pesquisadores explicam que o processo começa quando uma pessoa aprende um novo conhecimento e memoriza-o como fonte de inspiração para solucionar problemas futuros. Em algum momento do futuro, a pessoa se depara com um problema (Alvo) e procura lembrar-se de uma fonte adequada de conhecimento/ideia que poderia ajudá-lo a resolver esse problema. Esse é o passo mais difícil cognitivamente do processo: recuperar um conhecimento útil da memória (Fonte apropriada) para transferí-lo por analogia para solucionar um problema (Alvo). (Quadro 1).

Quadro 1. - Esquema do processo de analogia.
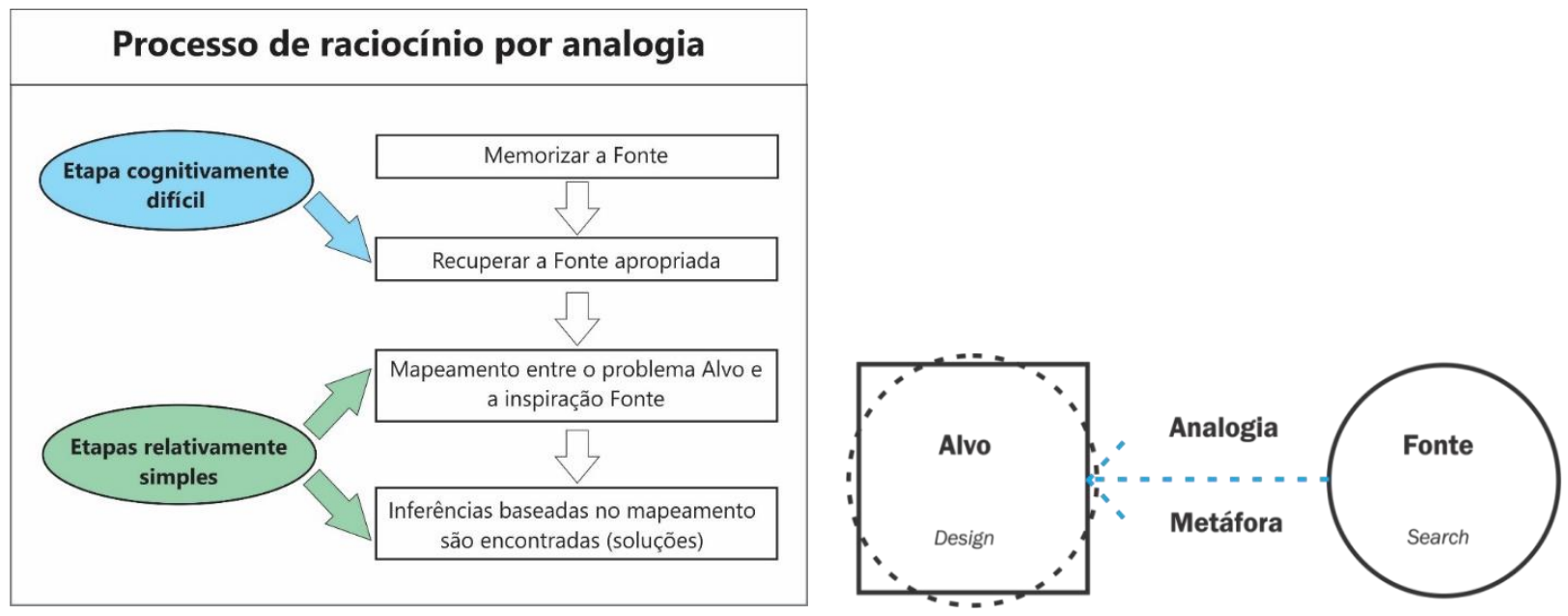

Fonte: adaptado de Gentner e Markman (1997).

O artigo "Analogies and Metaphors in Creative Design" (Hey et al, 2008), aponta que analogias e metáforas podem ser vistas como um mapeamento do conhecimento de uma situação para outra - ativado por um sistema de relações, representações e combinações entre as situações. Esse processo de comparação promove novas influências e permite interpretar problemas de novas maneiras, mais inovadoras e perspicazes. 


\subsection{Sinética}

Uma técnica específica para estimular analogias é a chamada sinética. A palavra sinética é derivada do grego e significa juntar elementos diferentes, aparentemente não relacionados entre si. A técnica de sinética foi desenvolvida por William Gordon, em 1957, como um aperfeiçoamento do método de brainstorming (BAXTER, 1998, pg 105).

Em seu livro "The Practice of Creativity", William Gordon reuniu suas experiências de muitos anos em treinamentos empresariais para desenvolvimento da capacidade criativa. Ele analisou horas de gravações de reuniões de negócios para solução de problemas que tinham resultados inconsistentes, e chegou à conclusão que era necessário um processo que estimulasse o pensamento aberto, o não julgamento e o uso de analogias para estimular resultados mais satisfatórios. Esse processo foi chamado por ele de sinética, e uma vez implementado levou a mais criatividade e inovação no ambiente empresarial. A sinética se aplica à integração de diversos indivíduos em um grupo de resolução de problemas. É uma teoria operacional para o uso consciente dos mecanismos psicológicos envolvidos na atividade criativa do homem a fim de estimular a solução de problemas (GORDON, 1961).

Um grupo de sinética é interdisciplinar, porém, "têm-se constatado a especial importância da participação de biólogos com estudos de biônica, fazendo analogias com seres vivos" (BAXTER, 1998, pg. 105). Aplica-se a sinética quando buscamos soluções inéditas, ou quando desejamos fazer mudanças profundas em produtos e processos. As sessões são lideradas por um profissional que sabe o problema exato a ser resolvido, porém, para evitar ideias conservadoras, ele não o expõe ao grupo. Ao contrário, estimula a exploração de todos os aspectos possíveis e amplos do problema, pensando em sua essência e em termos abstratos, sem se fixar na forma atual de um produto, por exemplo: um abridor de latas. O problema real é melhorá-lo, mas o líder propõe ao grupo trabalhar o problema, explorando o conceito de "abertura". "Assim, o grupo deve pensar em todas as formas de promover essa abertura, inclusive procurando analogias na natureza" (BAXTER, 1998, pg.106).

"A sinética reconhece dois tipos de mecanismos mentais": (BAXTER, 1998, p.106) transformar o estranho em familiar e o familiar em estranho. O primeiro tenta, por meio de nosso condicionamento mental, enquadrar o que nos parece novo em algo que nos é familiar. Deste modo, acabamos por resolver os problemas de forma conservadora, com soluções tradicionais, já experimentadas por nós. Para inovar, no entanto, é necessário romper com essa tendência conservadora e transformar o familiar em estranho; invertendo, desmontando, montando de forma diferente, torcendo, aglutinando para olhar o problema conhecido sob novo ponto de vista, explica Baxter (1998).

Segundo Gordon (1961) são quatro tipos de analogias usadas pela sinética: analogia pessoal, direta, simbólica e fantasiosa. Na analogia pessoal, a pessoa coloca-se mentalmente no lugar do processo, mecanismo ou objeto que pretende criar. Seguindo com o abridor de latas, você pode se imaginar como uma ponta de aço inox rompendo uma tampa de alumínio. Por sua vez, a analogia direta é muito usada na biônica, pois faz-se comparações com fatos reais, conhecimentos ou tecnologias. Usam-se imagens objetivas e impessoais para descrever o problema na analogia simbólica, por exemplo: "para o desenvolvimento de um mecanismo compacto para levantar pesos, imaginouse uma corda indiana, que sai do cesto e fica em pé" (BAXTER, 1998, pg. 106). Por último a analogia fantasiosa, aquela que costuma dar 'asas' à imaginação, fugindo das leis e normas estabelecidas. Ela apela para a irracionalidade, para fugir das regras convencionais na busca de ideias originais e soluções inovadoras (GORDON, 1961). 
Para entendermos a parte prática do uso da sinética, tomemos o exemplo dado por Baxter (1998), em que numa sessão de ideação sobre o desenvolvimento de um telhado que tivesse maiores aplicações que um telhado tradicional foi aplicada a técnica de sinética, especialmente a analogia direta por meio da biônica. Na preparação do problema o grupo (multidisciplinar) identificou que um telhado branco teria vantagens sobre o preto no verão e desvantagens no inverno. Então, se perguntaram: o que muda de cor na natureza? 0 grupo relacionou diversos animais que mudavam de cor sob determinadas circunstâncias, e chegaram ao exemplo do linguado, que fica branco quando está nadando sob areia branca, e escurece quando nada sobre o lodo escuro (mecanismo de proteção). Nesse momento, o biólogo presente no grupo passou a explicar cientificamente e detalhadamente o fenômeno o que provocou no restante do grupo uma série de ideias sobre como construir o telhado. Por fim, construíram uma analogia direta entre o linguado e o telhado. A solução foi usar um material preto com diversas bolinhas brancas embutidas nele. Quando o sol incidir sobre o telhado, este se aquece, e as bolinhas brancas se expandem emergindo a superfície.

\section{Design por analogia}

A prática de pegar emprestado ideias de outros domínios e áreas do conhecimento para resolver problemas técnicos pode ser chamado de design por analogia ${ }^{1}$ (KENNEDY, 2017). Um dos primeiros autores a mencionar este termo foram Huhns e Acosta (1988). Ambos da área de Inteligência Artificial, estavam preocupados com as capacidades estáticas e predeterminadas de sistemas de design baseado em conhecimento. Baxter extraiu do livro Techniques of Structured Problem Solving (Van Gundy, 1988), cento e cinco técnicas para estimular a criatividade e as relacionou com cada etapa do processo criativo, a saber: preparação, geração de ideias, seleção da ideia, revisão do processo criativo. O uso de analogias é uma das técnicas mais utilizadas para estimular a criatividade na etapa de geração de ideias (BAXTER, 2010). Por exemplo, uma equipe de design com o problema de projeto de criação de um dispositivo de dobrar roupa lavada, pode criar múltiplas representações linguísticas sobre o problema; tais como: rolar, compactar, colapsar, franzir, etc... Cada representação irá disparar diferentes analogias com outros tipos de dispositivos de dobrar, como por exemplo, dobradura de papel ou dobradura em metal (Quadro 2) (Hey et al, 2008).

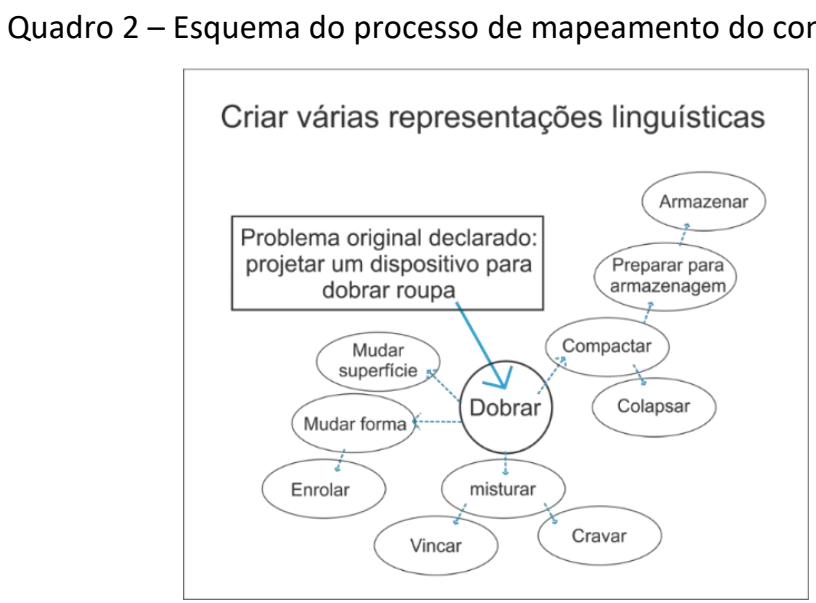

Fonte: adaptado de Hey et al. (2008)

\footnotetext{
${ }^{1}$ Também chamada de biomimética, biônica, design inspirado na natureza.
} 
Ainda segundo o estudo acima, o potencial para resolução criativa de problemas é mais perceptível, quando os domínios comparados são muitos diferentes e em campos de conhecimento distantes um do outro.

Segundo Baxter (1998, p.116), "analogia é uma espécie de raciocínio, em que propriedades de um objeto são transferidas para outro objeto diferente, mas com certas propriedades em comum". Ele enumera quatro tipos de analogias: proximidade (papel-lápis), semelhança (domingoferiado), contraste (gordo-magro) e causa-efeito (chuva, inundação). Elas são usadas para estimular o pensamento lateral (bissociação) e a capacidade de fazer novas associações, a fim de ultrapassar as ideias mais óbvias. Podem criar soluções completamente novas, descobrindo-se de que forma um problema semelhante é resolvido em um contexto diferente.

Ilustramos, com a imagem abaixo (Figura 1), o uso de analogia no design, ou seja - como a natureza comunica que a banana está estragada por meio de manchas e a transferência dessa "solução" para o rótulo de remédios, comunicando que o mesmo está fora da validade.

Figura 1 - Design gráfico de embalagem para remédios, usando analogia com a natureza.
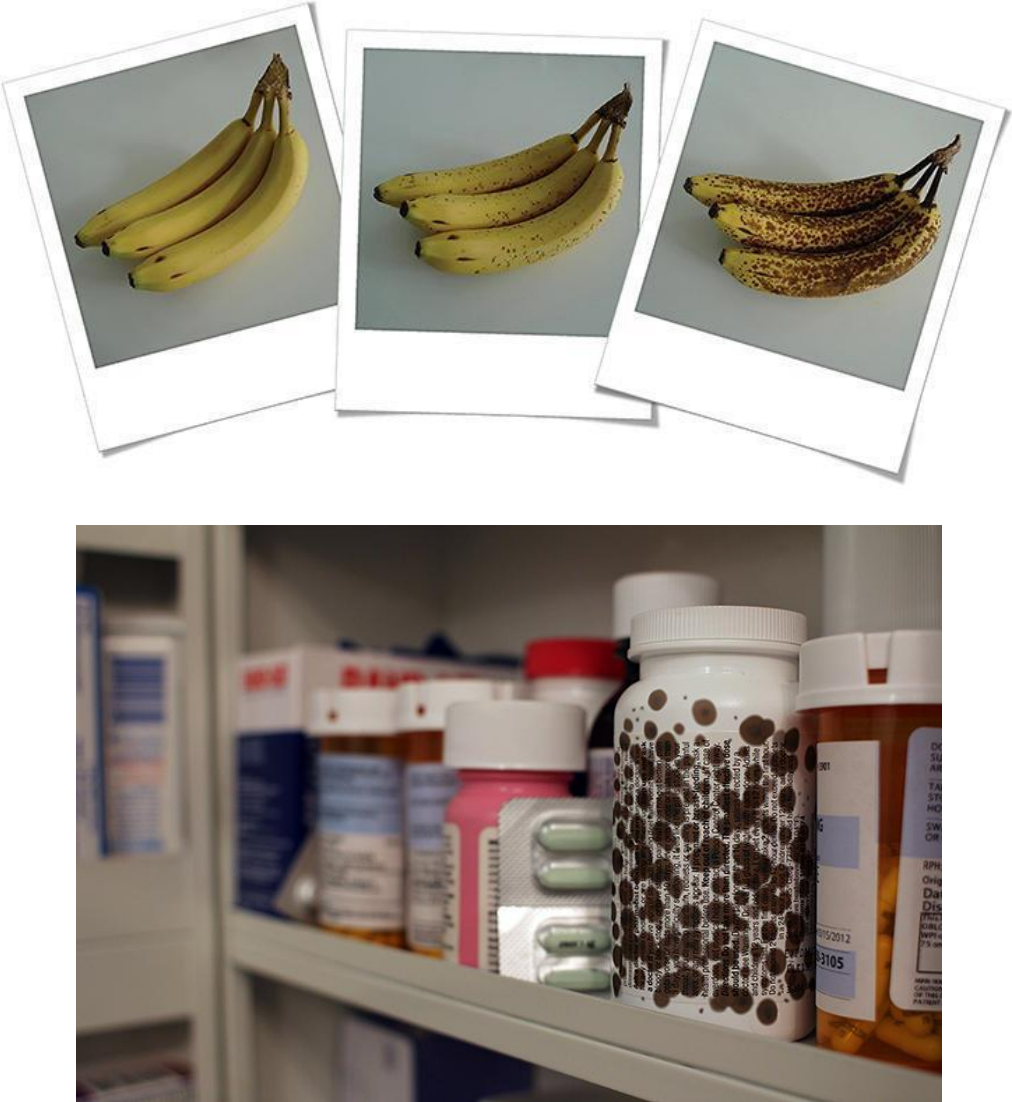

Fonte: Imagem disponível em <http://www.pinterest.com/pin/282178732877521603/>. Acesso em: 20 nov. 2014.

O jornal da Universidade de Cambridge, Reino Unido, destaca a relevância de ferramentas para apoiar analogias:

Design por analogia é um a poderosa parte do processo de design, entre uma larga variedade de modalidades usadas pelos designers, tais como descrição linguística, sketches e diagramas. Precisamos de ferramentas para dar apoio às capacidades das pessoas para encontrar e usar analogias. (SAMBASIVA R. BHATTAAND ASHOK K. GOEL, 1996, p. 131-136). 


\subsection{Analogias biológicas no design}

Analogias tem papel significativo e estratégico na resolução de problemas, tomada de decisão, percepção, memória, comunicação, criatividade e inovação, e uma excelente maneira de sistematizar seu uso no design é imergir na natureza para buscar fontes de inspiração. Por meio de analogias com a natureza, podemos transferir informação e significado de um sujeito particular (natureza) para outro sujeito particular (por ex.: produtos).

Nos últimos cem anos, especialmente depois da segunda guerra mundial, os cientistas começaram a pesquisar nas ciências biológicas respostas para problemas humanos e obtiveram excelentes resultados. O biólogo e matemático escocês Darcy Thompson, em seu livro On Growth and Form, 1917, explorou diversas geometrias de organismos naturais (Figura 2) e sua dinâmica de crescimento e processos físicos. Seus estudos influenciaram arquitetos, entre eles, Calatrava, Frei Otto, Renzo Piano, a terem como objetivo projetual o uso de princípios construtivos dos organismos presentes na natureza.

Figura 2 - Imagem contendo geometria de organismos naturais.

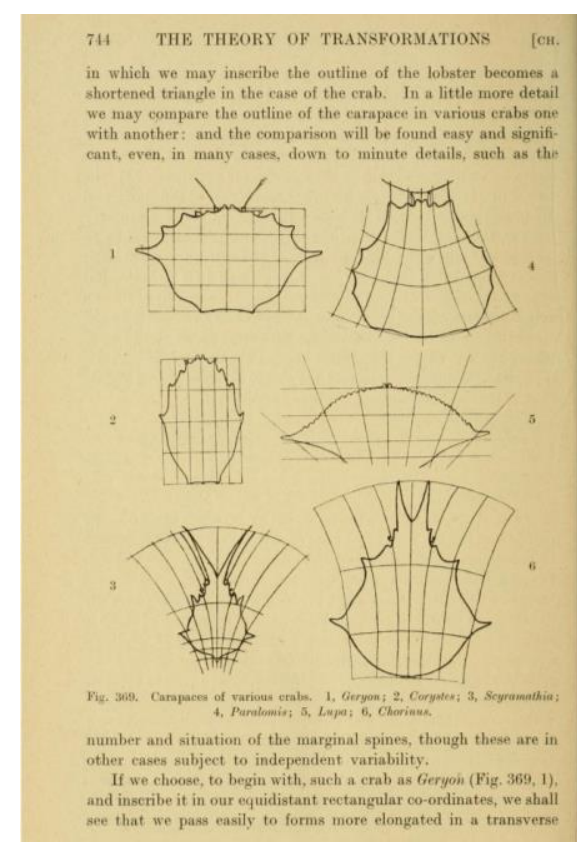

Fonte: On Growth and Form (1917).

O exemplo clássico de inspiração na natureza é a invenção do Velcro, criado por por George De Mestral em 1941. A ideia surgiu quando, após caminhada pelos Alpes Suíços, De Mestral retornou à sua casa com sementes de Arctium (carrapicho) coladas às suas roupas e aos pêlos de seu cão. Curioso, examinou o material através de um microscópio e conseguiu distinguir pequenos "ganchos" nas sementes que se entrelaçavam com filamentos do tecido, causando assim grande aderência entre as partes. Dessa observação e posterior pesquisa, De Mestral projetou um prendedor formado de duas partes: uma superfície com pequenos ganchos rígidos, como o carrapicho, e outra com pequenos laços flexíveis, como o tecido de sua calça. Assim nasceu o Velcro e a empresa Velcro Industries, fundada por De Mestral, e que hoje fatura milhões de dólares por ano graças às inúmeras aplicações do produto (Figura 3). 
Figura 3-Imagem de Arctium (carrapicho) e de velcro.

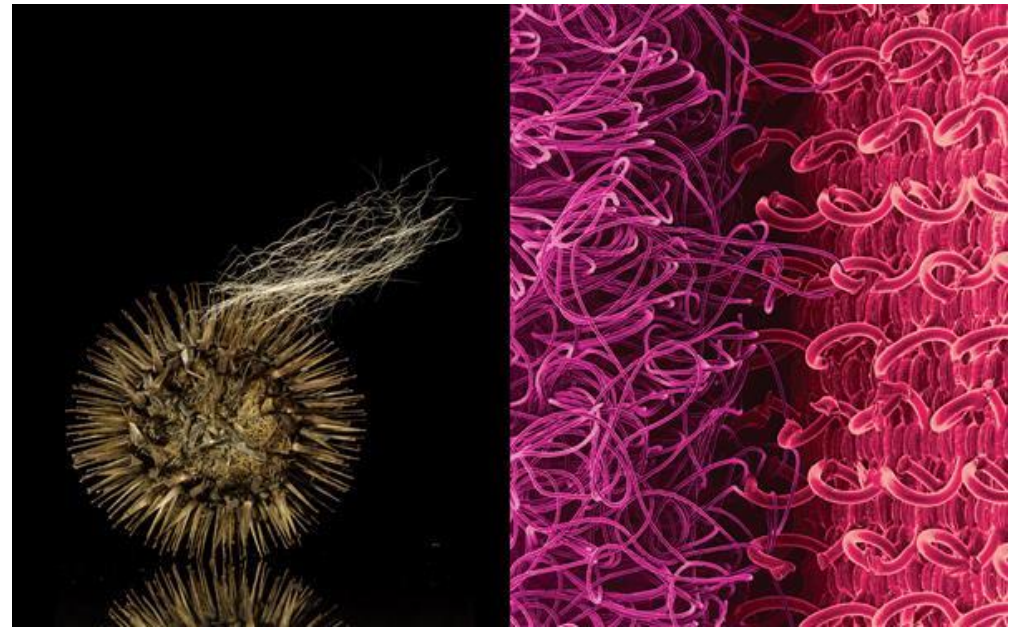

Fonte: Disponível em: <http://archive.audubonmagazine.org/features0909/greenDesign-InspiredByNature.html>. Acesso em: 20 nov. 2014.

A literatura científica, a partir de 1960, cunhou diferentes termos para caracterizar esse processo de imitar modelos naturais, sistemas e processos para resolver problemas humanos. São eles: biônica, biomimética, biomimesi, biognosis, bioinspiration, design bioanalogous, design biologicamente inspirado, biomimcry. Estes termos são muitas vezes considerados como sinônimos.

Em 1960, o Centro Wright Patterson, da aeronáutica dos Estados Unidos, em Ohio, promoveu um simpósio chamado Living prototypes - the key to new Technologies. No simpósio, o Major J.E.Steele apresenta o termo biônica como uma nova fronteira da tecnologia através da fusão de disciplinas biológicas e físicas. Steele definiu que "Biônica é a ciência dos sistemas cujo funcionamento é baseado em sistemas naturais ou que guardem qualquer analogia com estes". (Wright-Patterson Air Force Base, Ohio, Directorate of Advanced Systems Tech- nology, Wright Air Development Division, Air Research and Development Command, U.S. Air Force, 1961. Base de Dados: WorldCat). Os primeiros estudos realizados pela força aérea Americana, segundo descrito na publicação acima, foram sobre a estrutura dos olhos das abelhas, e tinham como objetivo projetar um sistema de orientação que desfrutasse de luz polarizada.

Em 1973, Victor J. Papanek, um dos estudiosos mais entusiastas da biônica, define o termo em seu livro Design for the real world:

Biônica significa 'a utilização de protótipos biológicos no design de sistemas sintéticos criados pelo homem'. Dito de maneira mais clara: se trata de estudar os princípios fundamentais da natureza e chegar a aplicação de princípios e processos às necessidades da humanidade. (PAPANEK, 1973, p. 190).

Papanek continua defendendo o uso da biônica:

O livro da natureza é um manual que nunca passará de moda. Nele, todos os problemas da humanidade e dos sistemas biológicos e bioquímicos já foram aceitos e resolvidos e mediante analogias, de maneira ótima. (PAPANEK, 1973, p. 190)

Em seu livro, acima citado, são detalhados inúmeros estudos biônicos com especial atenção às sementes: "se se deixa cair a cerca de um metro ou dois uma simples semente de Arce (Aceraceae Saccharum), ela descerá seguindo uma trajetória em espiral muito definida". Papanek (1973) relata que uma das aplicações mais interessantes, usando sementes de Arce, foi projetada por um 
estudante de design e consistia em um novo método para "sufocar" incêndios florestais: com plástico barato e leve se construiu uma semente artificial de Arce com $22 \mathrm{~cm}$ de comprimento que continha um pó extintor de incêndios. Quando as sementes artificiais estavam para cair sobre o fogo as correntes térmicas ascendentes das chamas faziam com que o plástico derretesse e liberasse o pó extintor. Esse experimento biônico fez chegar módulos extintores a zonas inacessíveis pelos bombeiros. Como defensor do Design Ético, Papanek conclui que:

Hoje já não é possível nem desejável desenhar nem um só produto que não esteja aparentado com seu entorno sociológico, psicológico e cidadão. Portanto, o designer deve encontrar analogias, utilizando não só a biônica, mas também os sistemas biológicos em sua aproximação ao design, tirados dos campos da ecologia e etologia (PAPANEK, 1973, p. 191).

A biônica também é definida como a junção da biologia com sistemas mecânicos e eletrônicos, resultando em produtos que funcionam como organismos vivos (Shu et al., 2011). O termo biomimética foi cunhado por Otto Schmitt, um cientista em biofísica e bioengenharia, no título de um artigo apresentado em 1969, no Terceiro Congresso Internacional de Biofísica. A definição de biomimética apareceu pela primeira vez no dicionário do Webster em 1974 como: o estudo da formação, estrutura ou função de substâncias e materiais biologicamente produzidos (como enzimas ou seda) e mecanismos e processos biológicos (como a síntese de proteínas ou fotossíntese), especialmente com a finalidade de sintetizar produtos semelhantes por mecanismos artificiais que imitam os naturais. (VINCENT et al., 2006). Seguiram-se outras definições do termo: "Biomimética é a realização de aplicações técnicas baseadas nos insights resultantes de fundamentos da investigação biológica" (SPECK \& SPECK, 2008, pg.3).

Benyus, cientista Americana e autora do livro: Biomimética - Inovação Inspirada pela Natureza (2003) define biomimética (Biomimicry) como uma nova ciência que estuda modelos da natureza e, em seguida, imita-os ou inspira-se neles para resolver problemas humanos. $O$ termo Biomimicry tem uma conotação de sustentabilidade.

Biomimética é uma abordagem para inovação sustentável, que busca inspiração nas coisas vivas (biologia). É um campo singularmente interdisciplinar que reúne biólogos, engenheiros, designers, empreendedores e outros, para resolver problemas por entender e aplicar estratégias da natureza para solucionar problemas humanos (BENYUS, 2011, http://biomimicry /digital_toolkit/index.html\#p=2).

Benyus (2003) apresenta essa nova ciência: "Biomimética" (Do grego bios, vida, e mimesis, imitação).

1. A natureza como modelo. A Biomimética é uma nova ciência que estuda os modelos da natureza e depois imita-os ou inspira-se neles ou em seus processos para resolver os problemas humanos. Podemos citar, como exemplo, uma célula de energia solar inspirada numa folha.

2. A natureza como medida. A Biomimética usa um padrão ecológico para ajuizar a "correção" das nossas inovações. Após 3,8 bilhões de anos de evolução, a natureza aprendeu: o que funciona. O que é apropriado. O que dura.

3. A natureza como mentora. A Biomimética é uma nova forma de ver e valorizar a natureza. Ela inaugura uma era cujas bases assentam não naquilo que podemos extrair da natureza, mas no que podemos aprender com ela." (BENYUS, 2003, pg 8)

Benyus propõe um mergulho na natureza para o conhecimento de infinitos exemplos de como revolucionar nossa vida:

Quando nos aprofundamos assim nas estruturas da natureza, ofegamos, assombrados, e, positivamente, nossas ilusões se desfazem. Percebemos que todas as nossas invenções já 
existem na natureza sob uma forma mais elegante e a um preço bem menor para o planeta. Nossas vigas e escoras já estão nas folhas do nenúfar e nas hastes do bambu. Nossos sistemas de aquecimento central e ar-condicionado são superados pelos estáveis trinta graus centígrados do cupinzeiro. Nosso radar mais sofisticado é surdo se comparado ao sistema de captação de frequências do morcego. E nossos "materiais inteligentes" não chegam aos pés da pele do golfinho ou da probóscide da borboleta. Até mesmo a roda, que sempre consideramos criação do homem, foi encontrada no minúsculo rotor que impele o flagelo da bactéria mais antiga do mundo (BENYUS, 2003, p.14).

Não só os campos do design de produto, da engenharia e arquitetura beneficiam-se com essas soluções. Benyus (2011) mapeou estudos de um grupo de cientistas e inventores que já fizeram inovações com base na natureza em áreas como a de medicamentos (a partir da observação de hábitos alimentares de animais) e de sistemas administrativos e econômicos baseados em princípios das florestas de sequóias e de nogueiras, que usam os detritos como recursos para a sobrevivência. Quatorze dessas invenções inteligentes inspiradas na natureza estão na plataforma on-line do Bloomberg Business, 2015 (Disponível em: <http://www.bloomberg.com>. Acesso em: 5 nov. 2014), que conecta os tomadores de decisão a uma rede dinâmica de informações, pessoas e ideias, com rapidez e precisão e oferece informações comerciais e financeiras, notícias e conhecimento em todo o mundo. Esse fato comprova a importância atual da biomimética para empresas que buscam a inovação.

Atualmente, diversos institutos de pesquisa científica (Harvard, Cambridge, Berkeley, MIT, etc...), especialmente ligados à engenharia, arquitetura, design e inteligência artificial, conduzem pesquisas em biomimética, vislumbrando inúmeras aplicações comerciais de suas invenções. Uma excelente referência para pesquisa em biomimética, atualmente, é o Departamento de Biologia Integrativa na Universidade da California, em Berkeley. Sob a direção de Robert Full, o PolyPEDAL Lab conduz estudos sobre o desempenho, a energética e dinâmica da locomoção animal, para transferir, com ajuda da computação e da engenharia, princípios da locomoção animal (como os animais se movem por músculos e esqueletos), para robôs. Uma dessas pesquisas estudou o Gecko (um pequeno lagarto do sul da França que se locomove em superfícies verticais lisas como o vidro), para inspirar robôs que escalam paredes (Figura 4).

Figura 4 - Imagem dos pés do Gecko e do protótipo do robô inspirado em seu funcionamento.

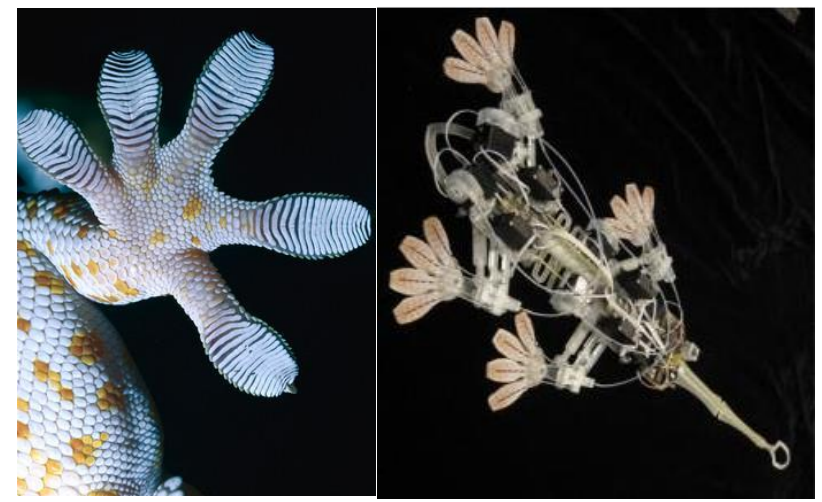

Fonte: Disponível em http://polypedal.berkeley.edu. Acessado em 7 dez 2015.

Os dedos dos pés dos lagartos também são alvo de pesquisas científicas em nanoescala, conduzidas pelo Computational Materials Research Group (CMRG) da Universidade do Estado de Oregon, nos Estados Unidos. Pesquisadores desse grupo, liderados por Alex Greaney, descobriram que Geckos possuem milhões de pelos (também chamados de "setas") minúsculos e ramificados em 
seus dedos. Essas "setas" são capazes de "ligar" e "desligar" a sua aderência, "colando" e "descolando" os pés de superfícies verticais por meio da aplicação de uma força de deslizamento paralela a essas superfícies. Esse sistema de adesão permite que uma lagartixa se movimente a uma velocidade equivalente a vinte comprimentos de seu próprio corpo por segundo com um mínimo de energia. Desvendar tais mecanismos pode ser crucial, por exemplo, para criar adesivos e colas mais eficazes, explicam os cientistas. (http://research.engr. oregonstate.edu/greaney/content/ simulation-gecko-inspired-dry-adhesion-system).

O estudo do Gecko adquiriu enorme relevância hoje nos Estados Unidos, tanto que o atual estágio da pesquisa deu origem ao projeto RiSE e está sendo financiada pelo Programa Biodynotics do Defense Advanced Research Project Agencys (DARPA) e reúne as universidades americanas da Pensilvânia, Berkeley, Stanford e Harvard. O projeto RiSe tem como objetivo criar um robô com capacidade de andar na terra e escalar superfícies verticais (Figura 5).

Figura 5 - Testes com o protótipo do RiSE.

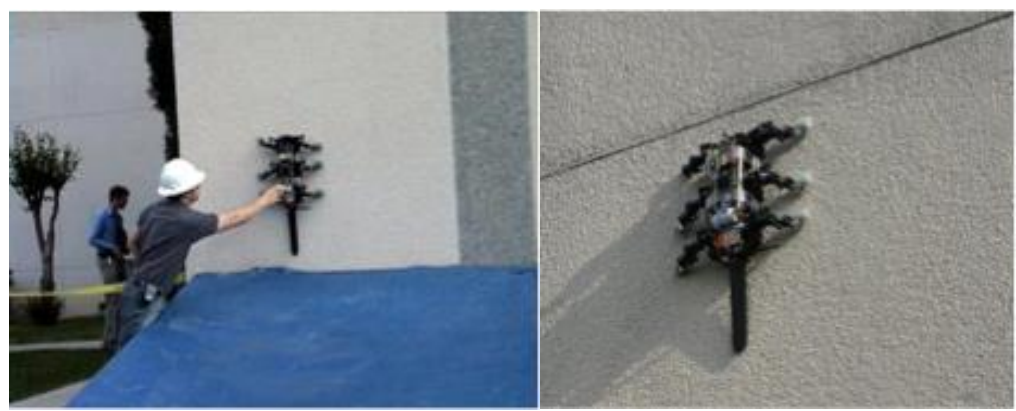

Fonte: Disponível em: < http://kodlab.seas.upenn.edu/ rise> Acesso em: 6 dez. 2015.

É interessante comparar esse exemplo de Biomimética, do ano de 2015, com um exemplo utilizando o mesmo animal (Gecko), do ano de 1989, em que designers decodificaram a geometria e funcionamento das patas em forma de lâminas maleáveis para inspirar algumas solas de sapatos para caminhadas em terrenos de rocha escorregadia. (Figura 6).

Figura 6 - Imagem de Gecko e solado de sapato.
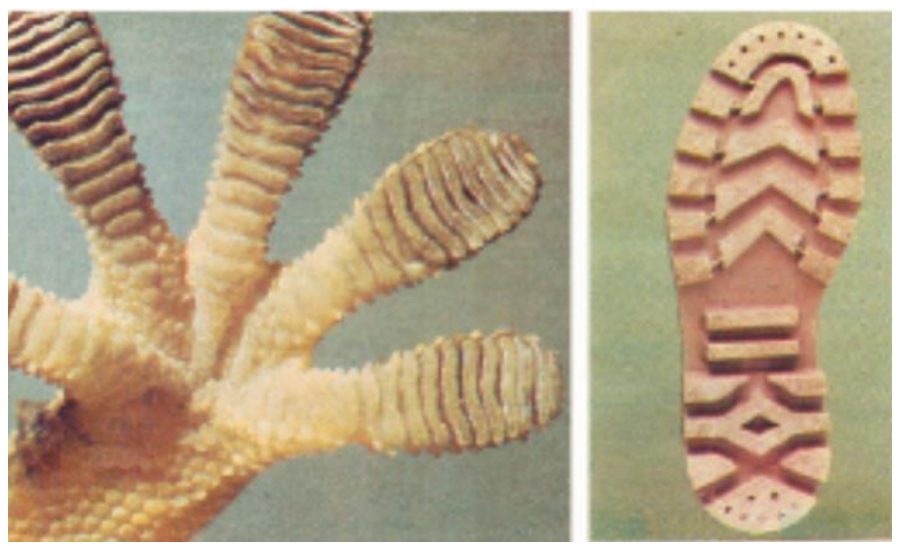

Fonte: Revista Manchete em 9/12/1989.

Verifica-se uma evolução considerável na transferência das analogias para produtos apresentadas nos exemplos acima (de solas de sapato para robôs), uma vez as tecnologias disponíveis hoje permitem um maior número e complexidade de dados, informações e visualizações em nanoescalas, capazes de revelar e explicar com maior acuidade o funcionamento de sistemas naturais. 
O Instituto WYSS para Engenharia Biologicamente Inspirada (WYSS), na Universidade de Harvard, Boston, descreve a sua missão:

Nossa missão é desenvolver materiais biologicamente inspirados e dispositivos que solucionarão problemas médicos e ambientais críticos, e traduzir essas tecnologias transformadoras em produtos que tenham um impacto na sociedade e no mundo (http://wyss.harvard.edu/viewpage/264).

É o caso do RoboBees (Figura 7), um o robô inspirado na biologia de uma abelha. Os pesquisadores do WYSS vislumbram uma série de aplicações comerciais para os Robobees, que vão desde usos para agricultura (colheita e polinização), até salvamento em missões após desastres naturais, mapeamento do clima, de tráfego e ambiental. Para resolver problemas de projeto e implementar a produção em massa, os RoboBess contam com o financiamento externo da National Science Foundation. Os RoboBees são micro veículos aéreos autônomos, medindo cerca de metade do tamanho de um clipe de papel, e pesando menos de um décimo de uma grama. Eles voam usando "músculos artificiais" compostos de materiais que contraem quando uma voltagem é aplicada.

Figura 7 - Imagem do RoboBees.
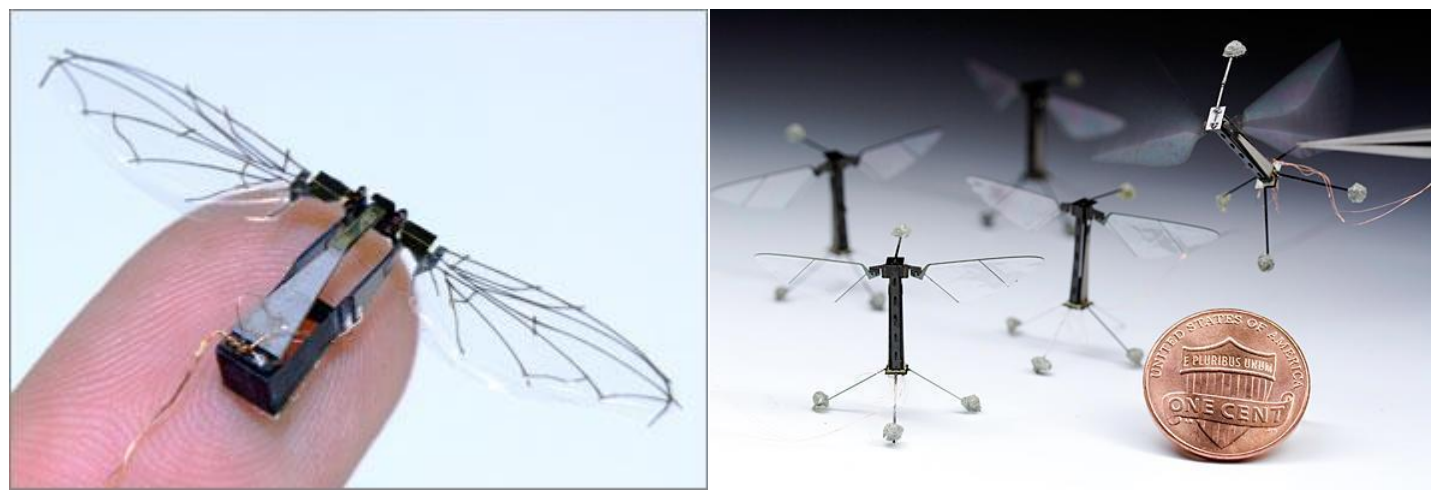

Fonte: Disponível em:<http://wyss.harvard.edu/viewpage/204/bioinspired-robotics>. Acesso em: 7 dez. 2015.

Hugh Herr dirige o grupo de pesquisa Biomecatrônica no MIT Media Lab' s. Herr, que é amputado dos membros inferiores, projetou próteses de pernas biônicas que, segundo ele, "imitam a natureza" pois emulam o funcionamento de joelhos biológicos, tornozelos e panturrilhas. (Figura 8).

Figura 8 - Hugh Herr usando a prótese biônica.

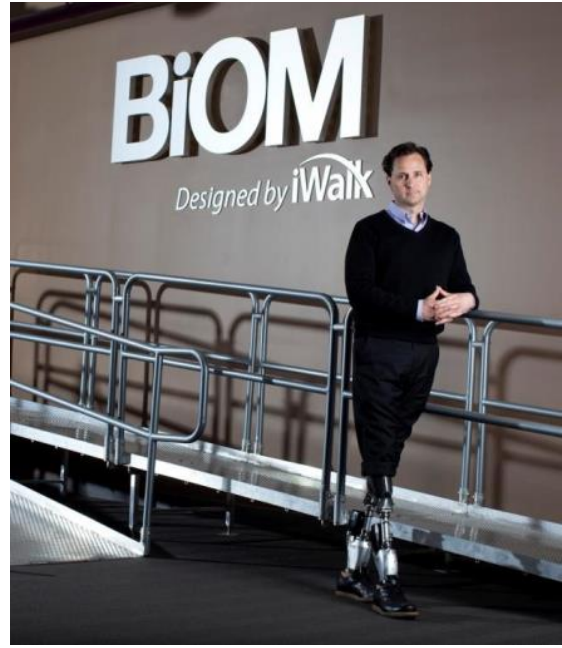

Fonte: Disponível em: <http://www.activewirehead.com/bionic-leg-hugh-herr/>. Acesso em: 7 dez. 2015. 
Ele próprio é usuário das próteses que o grupo de Biomecatrônica (MIT) criou, e que continuam sendo aperfeiçoadas em sua biomecânica e controle de movimento biológico. Herr, também criou a empresa BiOM, que produz tecnologia de propulsão biônica para substituir músculos perdidos e tendões. O Sistema T2 da BiOM fornece energia auxiliar para melhorar a mobilidade das pessoas com amputações de membros inferiores, e com isso facilitar a reabilitação humana.

Podemos, também, exemplificar o uso de biomimética na indústria automobilística com projeto de um carro conceito feito em parceria com o designer Ross Lovegrove e a fabricante de carros francesa, Renault (Figura 9). O resultado é o desenvolvimento de uma sintax visual baseada em padrões orgânicos. Lovegrove afirma que a intenção é "revelar os projetos da natureza" e transferí-los para uma nova linguagem de design.

Figura 9 - Carro Biomimético Renault.
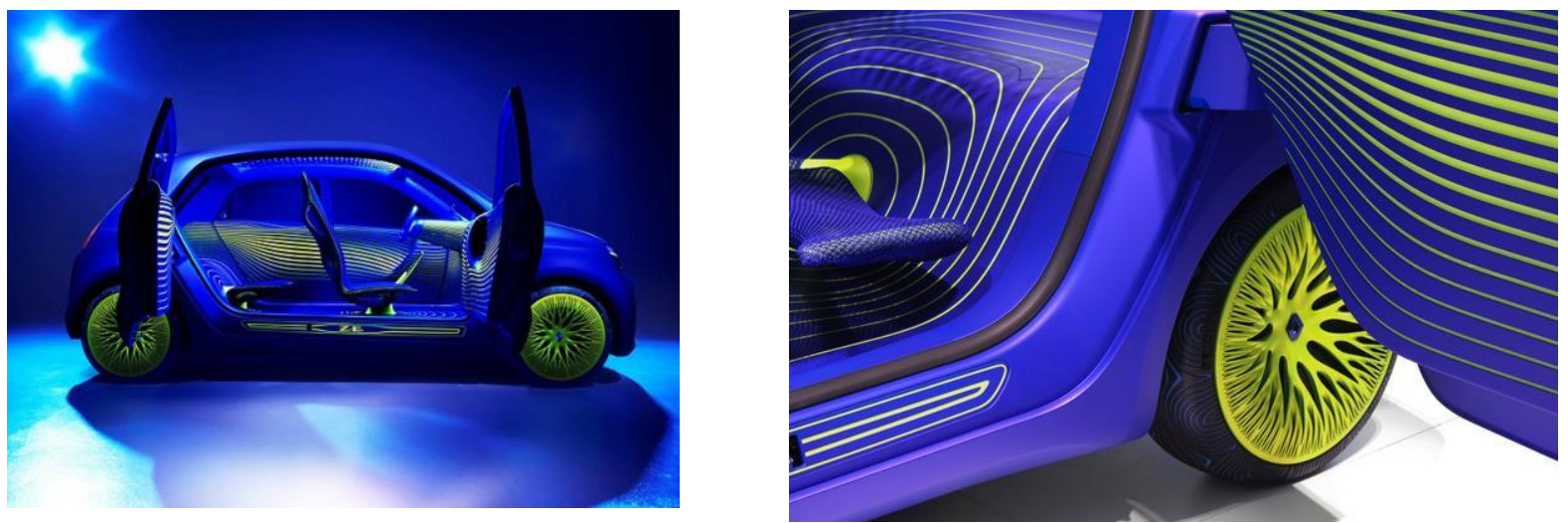

Fonte: Disponível em: http://www.fastcodesign.com/> Acesso em: 7 dez. 2015

Tecnologias emergentes estão cada vez mais disponíveis para os designers. O projeto Pingente Relicário (Scagliusi, 2016) apresenta o processo de utilização de Microtomografia Computadorizada, do Processamento Digital de Imagens e da Impressão 3D para respectivamente a aquisição da forma tridimensional de uma semente para tratamento e realização de modelo digital para a impressão 3D de modelo em cera de uma joia.

Figura 10 - Pingente Relicário.

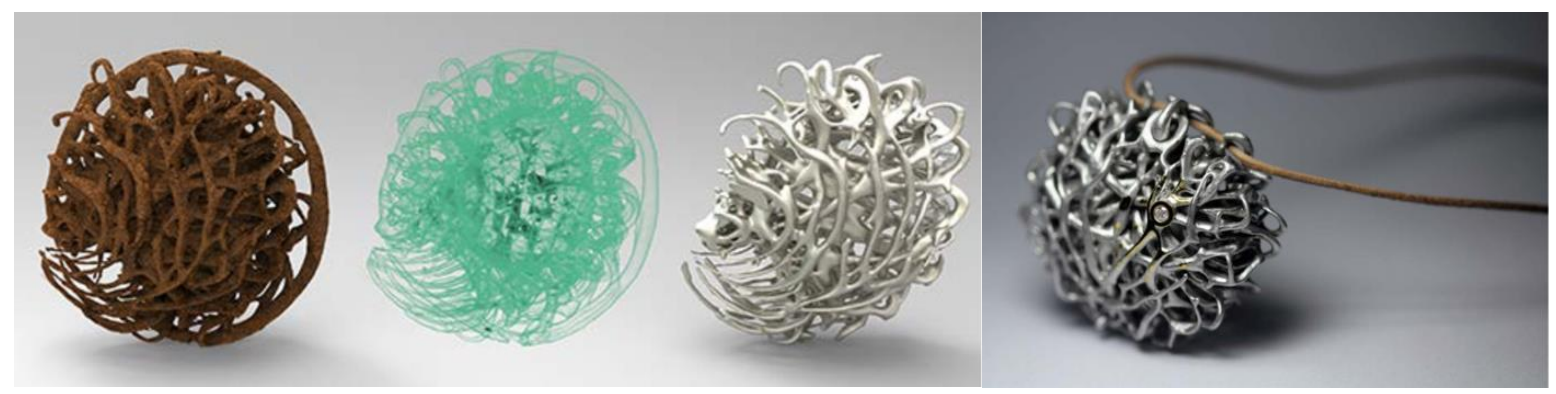

Fonte: Scagliusi (2016)

Ainda no segmento de adornos pessoais, podemos destacar o exemplo do Nervous Systems onde o Design Generativo, sistema de venda parametrizado e impressão 3D sob encomenta, viabilizam um modelo de negócios totalmente novo. Padrões da natureza como o coral são integrados a sistemas parametrizados online que permitem o consumidor interferir e selecionar materiais e cores para uma impressão $3 \mathrm{~d}$ em plástico ou metal (https://n-e-r-v-o-u-s.com). 


\section{Conclusão}

Esse artigo destacou a importância da criatividade para o design e como o processo criativo pode ser aprendido, desenvolvido e sistematizado por meio de diversas ferramentas e técnicas, sendo uma delas o uso de analogias - especialmente analogias biológicas como a biomimética impulsionada pela tecnologia. O problema seria a transferência do efeito encontrado na natureza para o problema de design. Um breve panorama histórico dessa nova área de conhecimento foi apresentado, explicitando-se, por meio de exemplos, ser ela uma abordagem promissora para criação de soluções de design inovadoras.

Consideramos que existe um ambiente ideológico favorável à incorporação da biomimética no design por conta da questão da sustentabilidade. No entanto, nem sempre um projeto que usa analogias da naturesa resulta em um projeto sustentável. Como foi apresentado anteriormente, outros fatores favorecem a utilização de analogias da natureza no design e estão relacionadas com as novas tecnologias.

Em um primeiro passo dentro do processo de design, o problema da recuperação da informação citado por Gentner e Markman (1997) é minimizado pelas bases de dados disponíveis. Podemos destacar o BIOMIMICRY 3.8 (2014) ou o Ask Nature ${ }^{2}$. Nestes sites, é possível fazer buscas e encontrar referências de estudos biológicos sobre os problemas encontrados em projetos. Mas também estão disponíveis métodos e modelos como o "Biology to design" (Biologia para Projetar), abordagem metodológica do "Biomimicry Design Lens" (Lentes Biomiméticas) (2014).

A extração direta de elementos da naturesa pelos designers passa a ser possível na medida em que scaners tridimensionais e outros sistemas de captura de imagens se tornam mais acessíveis. É importante destacar o papel dos softwares e do poder dos computadores que permitem que os sitemas generativos morfogenéticos produzam formas cada vez mais complexas baseados, por exemplo, em modelos de crescimento naturais. Por fim, estas formas complexas só se viabilizam através de processos de simulação digital e física. Softwares de simulação de esforços e a impressão 3D possibilitam testes digitais e físicos de maneira mais precisa e com menores custos. Em um cenário promissor a bioimpressão parece integrar todos estes fatores do design inspirado na natureza, uma vez que utiliza a tecnologia de impresão 3D e biomateriais entre outras coisas para fabricar partes biomédicas que imitam as características do tecido natural.

\section{Referências}

BAXTER, Mike. Projeto de Produto. São Paulo: Ed. Blucher, 2010.

BENYUS, Janine. Biomimética: inovação inspirada pela natureza. São Paulo: Ed. PensamentoCultrix, 2003.

BIOMIMICRY 3.8. Biomimicry Design Lens. Licenced under creative commons BY-NC-ND. Disponível em: http://biomimicry.net/about/biomimicry/biomimicry-designlens>. Acesso em: 21 nov. 2014.

GENTNER, Dedre; MARKMAN, Arthur B. Structure Mapping in Analogy and Similarity. USA: American Psychological Association, 1997.

GORDON, William J.J. Synectics: The Development of Creative Capacity. New York: Harper \&

\footnotetext{
${ }^{2} \mathrm{Http}: / /$ www.biomimicry.org e http://www.asknature.org.
} 
Brothers, 1961.

HEY et al. Analogies and Metaphors in Creative Design. International Journal of Engineering Education, Volume 24, Número 2, 2008

HUHNS, M; ACOSTA, R. Argo: a system for design by analogy. IEEE Expert. 3, 3, 53, Jan. 3, 1988.

J.E.STEELE. Living prototypes - the key to new Technologies. Wright-Patterson Air Force Base, Ohio, Directorate of Advanced Systems Technology, Wright Air Development Division, Air Research and Development Command, U.S. Air Force, 1961. Base de Dados: WorldCat

KENNEDY, EB. Biomimicry: Design by Analogy to Biology. Research-Technology Management. 6, 51, 2017.

NATIONAL ACADEMY OF ENGINEERING. Educate to Innovate: factors that influence innovation. The National Academies Press. Washington-DC, 2015.

PAPANECK, Victor. Design for the real world. London: Paladin, 1973

ROBINSON, Ken. Libertando o Poder Criativo. São Paulo: HSM Editora, 2012.

SAMBASIVA R. BHATTA AND ASHOK K. GOEL. Cambridge Journal p. 131-136, 1996.

SCAGLIUSI, S., Pingente Relicário, Anais do 12 D\&D Design 2016, Blucher Design Proceedings, Belo Horizonte, 2016.

SHU, H. et al. Biologically inspired design. CIRP Annals - Manufacturing Technology 60 (673-693). Canadá, 2011.

SPECK, T; SPECK, O. Process sequences in biomimetic research. WIT Transactions on Ecology and Environment-Volume 114. Alemanha, 2008.

THOMPSON, Darcy. On Growth and Form, 1917.

Homepages:

http://www.pinterest.com/pin/282178732877521603/

http://polypedal.berkeley.edu/

http://wyss.harvard.edu/

http://www.fastcodesign.com/

http://biomimicry.org

http://wyss.harvard.edu/viewpage/204/bioinspired-robotics

http://kodlab.seas.upenn.edu/ rise

http://www.bloomberg.com/slideshow/2013-08-18/14-smart-inventions-inspired-by-nature-

biomimicry.html\#slide6site

http://www.activewirehead.com/bionic-leg-hugh-herr

http://www.asknature.org 